East African Medical Journal Vol. 85 No. 4 April 2009

VAGINAL HISTOLOGICAL CHANGES OF THE BABOON DURING THE NORMAL MENSTRUAL CYCLE AND PREGNANCY

A. Nyachieo, BSc., MSc, Research Fellow, N. M. Kiulia, DMLS., HND, Lab Technologist, M. M. Arimi, BSc, Research Assistant, D. C. Chai, BVM, Senior Veterinary Surgeon, J. M. Mwenda,MPhil., PhD,Principal Research Scientist,Department of Reproductive Health and Biology, Institute of Primate Research, P.O. Box 24481-00502, Karen, Nairobi, Kenya

Request for reprints to: Dr. J. M. Mwenda, Institute of Primate Research, P. O. Box 24481- 00502, Karen, Nairobi, Kenya

\title{
VAGINAL HISTOLOGICAL CHANGES OF THE BABOON DURING THE NORMAL MENSTRUAL CYCLE AND PREGNANCY
}

\author{
A. NYACHIEO, N. M. KIULIA, M. M. ARIMI, D. C. CHAI and J. M. MWENDA
}

\begin{abstract}
Background: A baboon, a non-human primate, is phylogenetically close to human and has been used to study in detail aspects of reproductive physiology that cannot be studied in humans for ethical reasons.

Objective: To determine the histological changes in baboon vagina associated with cyclic variations during normal menstrual cycle.

Setting: The experiments were carried out at Institute of Primate Research (IPR), Karen, Nairobi, Kenya.

Subjects: Nine adult healthy female olive baboons were used in this study. These baboons were monitored over a period of one year and found to have regular menstrual cycles. The vaginal biopsies were taken at different menstrual stages, fixed in $10 \%$ formalin and processed to evaluate histological changes.

Results: Observation of the histological sections of the biopsies by light microscopy showed that there were histological changes associated with cyclic variations in female olive baboon. During the luteal phase, menstrual phase and pregnancy the squamous epithelium was very thin. The layer gradually thickens throughout the proliferative phase and was thickest during the ovulation period.

Conclusion: The changes in squamous epithelium suggest that the baboon vagina undergoes histological changes throughout the menstrual cycle which may be associated with hormonal variations. The data from this study also suggest that olive baboon is a good model for investigating possible effects of hormonal contraceptives on vaginal epithelium and the mechanism of female heterosexual transmission of HIV.
\end{abstract}

\section{INTRODUCTION}

A baboon model has been used to provide detailed understanding of reproductive physiology applicable to human reproductive health (1). For instance a baboon, has led to characterisation of the pathogenesis of endometriosis, a debilitating and painful disease affecting women (2-4). Earlier studies, using the baboon, correlated the changes in hormonal levels to the changes on the perineal sex skin which has led to easier follow up of baboon menstrual cycle $(1,5)$. These stages have been classified as: menstrual phase (stage 7), post menstrual (stage 1), pre-ovulation (stage 2), ovulation (stage 3), post-ovulation (stage 4), luteal (stage 6), pre-menstrual (stage 0) and pregnancy (stage 8). However, no studies exist on the correlation of vaginal epithelial histological changes during the menstrual cycle and perineal sex skin changes. Such studies are important especially with the recent studies suggesting that infection and entry of viruses such as human immunodeficiency virus (HIV) may be dependent on the reproductive state of the host and the stage of the menstrual cycle (6). In women, limited studies suggest that sex hormones play an important role in regulating the female reproductive tract (7) with vaginal epithelial thickness increasing in the pre-ovulatory and ovulatory phases but decreasing in the luteal phase probably as a result of changes in oestrogen and progesterone production respectively (7). However, due to ethical reasons, it has not been possible to perform a detailed study on the correlation between vaginal histological changes, hormonal changes and HIV infections in human. On the other hand, a baboon which has a 
similar reproductive physiology to human, is not an endangered species and is readily available in sub-Saharan Africa for research (8). In this regard, female baboon model can be used to understand the effect of exogenous (hormonal based contraceptives) and endogenous (normal circulating hormones) on vaginal histology. In this study, we evaluated the vaginal histological changes in the baboon during the menstrual cycle.

\section{MATERIALS AND METHODS}

Animal selection: Nine healthy adult female baboons (Papio anubis) (mean \pm SD [15.2 $\pm 2.03 \mathrm{Kg}]$, range 12.5$17.6 \mathrm{Kg}$, median $15.3 \mathrm{Kg}$ ), with regular menstrual cycles(were negative for Simian immunodeficiency virus (SIV) and tuberculosis (TB) were selected.These included: PAN 2948, PAN 2952, PAN 2879, PAN 2804, PAN 2945, PAN 2955, PAN 2852, PAN 2840 (second trimester pregnancy [day 117 of pregnancy]) and PAN 2944 (third trimester pregnancy [day 126 of pregnancy]). They included feral animals trapped mainly from Kibwezi in Eastern Kenya, Gilgil and Namanga (Rift valley), Kakamega in Western Kenya and animals housed at the Institute of Primate Research (IPR) primate colony. The animals were fed on commercial monkey chow with fruits and vegetable supplementation three times a week; water was provided ad libitum. All animal procedures and care were conducted in accordance with internationally accepted principles for laboratory animal use, care and institutional standard operating procedures. The baboons' menstrual cycles were closely monitored by the IPR Animal Resource Department animal health technicians by daily observing perineal sexual skin changes as described $(1,5)$.

\section{Tissue collection}

Collection ofvaginal biopsies: Briefly, the baboons were sedated by intramuscular injection (i.m) injection $0.2 \mathrm{ml} / \mathrm{Kg}$ of a mixture containing $10 \%$ Ketamine $\mathrm{HCl}$ and $10 \%$ xylazine. A vaginal speculum was placed to expose the external os of the cervix. A probe with centimetre markings was used to measure the distance from the cervix to about $1 \mathrm{~cm}$. At this point, an endoscopic cup (Karl Storz, GmbH \& Co. $\mathrm{KG}$, Germany) was used to pinch the tip of the epithelium. One vaginal biopsy was collected from the mid-lateral side of the vaginal wall in each of the baboons which were at different stages such that all stages were represented. The biopsies taken were from PAN 2852 (stage 1), PAN 2948 (stage 2), PAN 2879 (stage 3), PAN 2952 (stage 4), PAN 2945 (stage 6), PAN 2955 (stage 0), PAN 2804 (stage 7) and from stage 8 which was represented by two pregnant baboons at different gestation periods that is, PAN 2840 [day 117 of pregnancy that is, second trimester]) and (PAN 2944 [day 126 of pregnancy that is third trimester]).

Tissue processing and examination: The vaginal biopsies were fixed in 10\% formalin and dehydrated progressively higher concentrations of ethyl alcohol (50\%, 70\%, 80\%, $90 \%$ and absolute alcohol), after which they were immersed in Toluene. Subsequently they were processed through Toluene three times and then infiltrated in paraffin wax mixture in an oven (Oven model-5831, National appliance Co., Portland, Oregon, USA). The tissues were then oriented in a perpendicular fashion on a piece of embedding ring and embedded in molten wax. Tissue sections (of about 3-4 $\mu \mathrm{m}$ thick) were sectioned using rotary microtome (Leitz-1512, West Germany) mounted on slides, rehydrated and stained using haematoxylin and eosin for histological examination using a light microscope (Olympus BX50, Model BX50F-3, Japan).

Baboon perineal skinstaging:Perineal sexskinevaluation was used toevaluate the cyclic changes during baboon menstrual cycle (1). The dramatic changes in colour and size of perineal skin occur through out the cycle. The stage of the baboon is indicated by degree of inflation and tumescence (5). In this study perineal sex skin was categorised and analysed into phases; Postmenstrual phase (1), pre-ovulation phase (2), ovulation phase (3), post-ovulation/secretory (4), luteal phase/secretory (6), pre-menstrual phase (0), menstruation phase (7), pregnancy phase (8). The sex skin for some phases is shown (Figure 1a and 1b).

\section{RESULTS}

Evaluation of vaginal biopsy histological sections by light microscopy indicated the following histological observations (summarised in Table 1 and Figures 2(a-h). 
Table 1

Baboon vaginal histological observations

\begin{tabular}{|c|c|c|c|c|}
\hline Phase & $\begin{array}{l}\text { Cycle } \\
\text { stage }\end{array}$ & $\begin{array}{l}\text { First day } \\
\text { of cycle stage }\end{array}$ & $\begin{array}{l}\text { Last day of } \\
\text { cycle stage }\end{array}$ & $\begin{array}{l}\text { Histological microscopic } \\
\text { observations }\end{array}$ \\
\hline Menstrual phase & 7 & $1^{\text {st }}$ & $3^{\text {rd }}$ & $\begin{array}{l}\text { Thin EL, diminished IC and SC. Basal } \\
\text { and parabasal cells developing }\end{array}$ \\
\hline Post menstrual & 1 & $4^{\text {th }}$ & $5^{\text {th }}$ & $\begin{array}{l}\text { Average size EL, increased/more uniform } \\
\text { SC and IC. }\end{array}$ \\
\hline Pre-ovulation & 2 & $6^{\text {th }}$ & $8^{\text {th }}$ & $\begin{array}{l}\text { Thick/increasing EL, larger basal and } \\
\text { parabasal cells }\end{array}$ \\
\hline Ovulation & 3 & $9^{\text {th }}$ & $13^{\text {th }}$ & Very thick EL, and many SC \\
\hline Post-ovulation & 4 & $14^{\text {th }}$ & $18^{\text {th }}$ & $\begin{array}{l}\text { Thick but diminishing EL, clumping of } \\
\text { basal and parabasal cells. }\end{array}$ \\
\hline Luteal & 6 & $19^{\text {th }}$ & $21^{\text {st }}$ & $\begin{array}{l}\text { Thin EL, little SC and IC crowded but } \\
\text { small size BC }\end{array}$ \\
\hline Pre-menstrual & 0 & $22^{\text {nd }}$ & $34^{\text {th }}$ & $\begin{array}{l}\text { EL minimum, little SC and IC but high } \\
\text { leucocytes in number }\end{array}$ \\
\hline \multicolumn{5}{|l|}{ Pregnancy } \\
\hline $2^{\text {nd }}$ Trimester & 8 & $60^{\text {th }}$ & $120^{\text {th }}$ & $\begin{array}{l}\text { Very thin EL, little SC and IC but high } \\
\text { leucocytes in number }\end{array}$ \\
\hline \multicolumn{5}{|l|}{ Pregnancy } \\
\hline $3^{\text {rd }}$ Trimester & 8 & $120^{\text {th }}$ & $180^{\text {th }}$ & $\begin{array}{l}\text { Very thin EL, very little SC and IC but } \\
\text { high leucocytes in number }\end{array}$ \\
\hline
\end{tabular}

$\mathrm{EL}=$ Squamous Epithelial Layer, $\mathrm{SC}=$ Superficial cells, $\mathrm{IC}=$ Intermediate Cells, $\mathrm{BC}=$ Basal Cells Stage day $=$ counted from $1^{\text {st }}$ day of menstruation

Table 1 shows the different types of cells and epithelial thickness variation observed during the various stages of the baboon menstrual cycle. This table also shows the first and the last days of the cycle stages

\section{Figure 1a and $\mathbf{1 b}$}

Some of perineal sex skin stages studied (stage 6 and 0 )
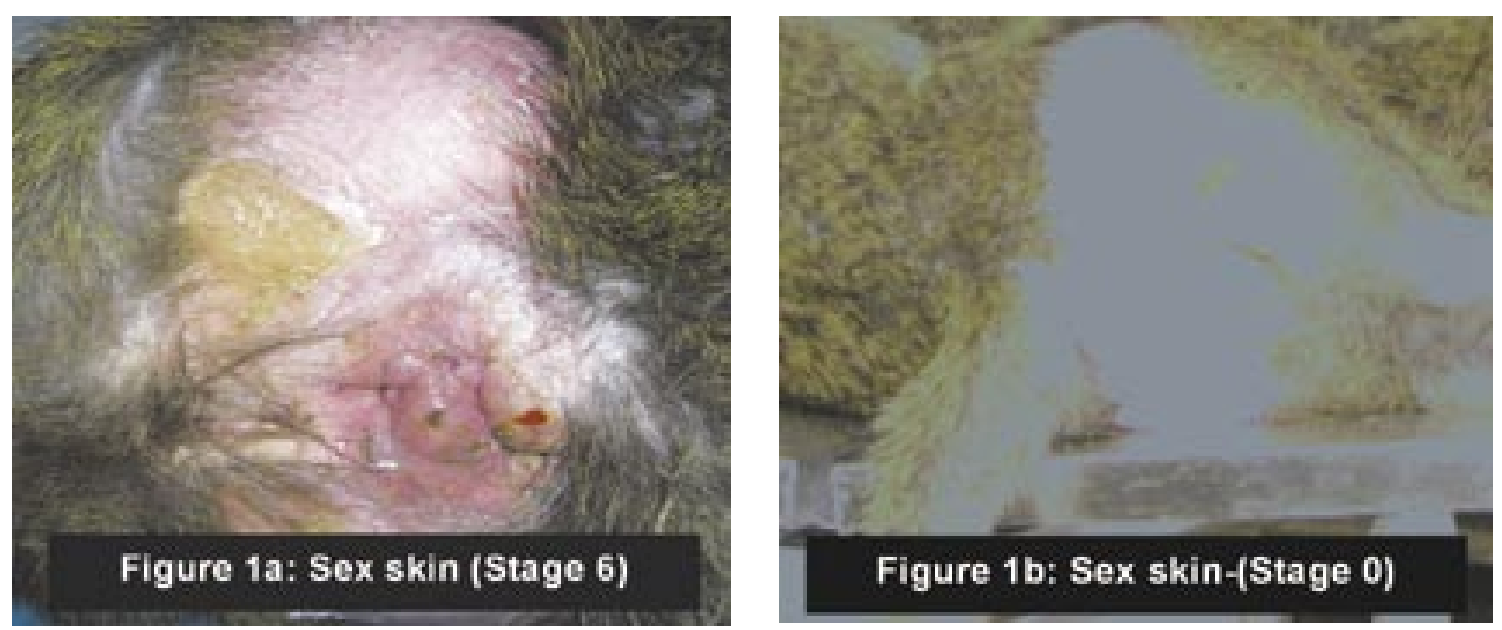
Figures 2(a-d)

Haematoxylin and eosin staining of female baboon vaginal biopsy during the menstrual cycle (follicular and ovulatory phases)
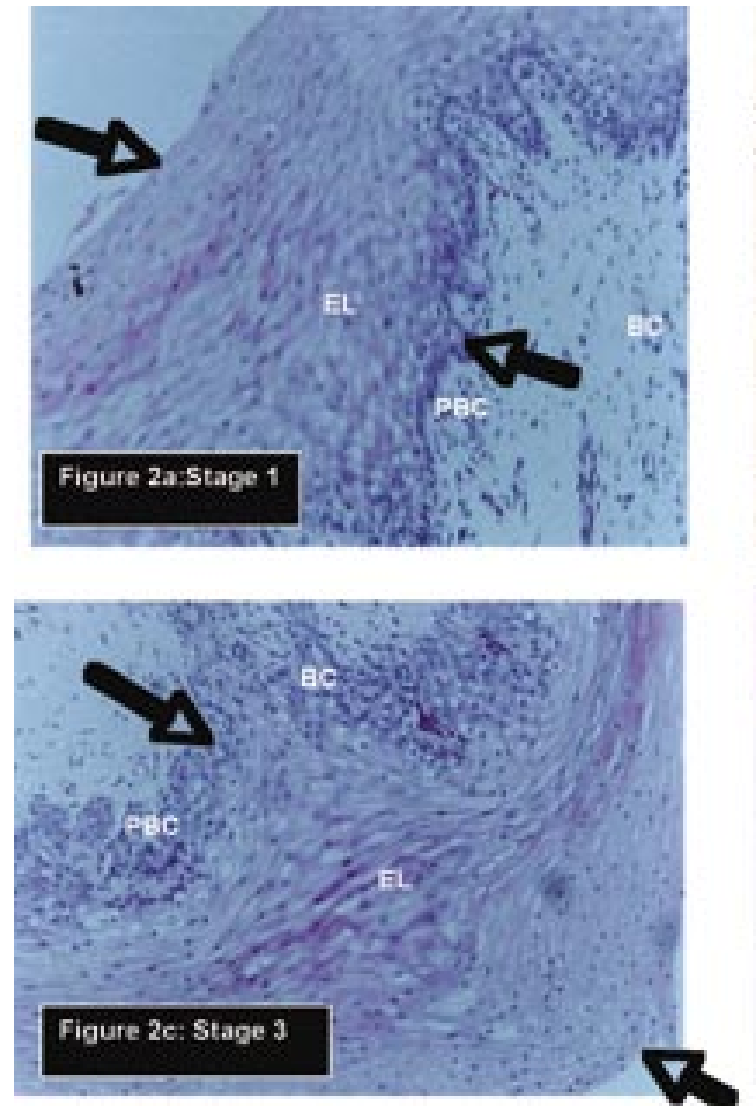

$\mathrm{BC}=$ Basal Cells

PBC $=$ Parabasal Cells

$\mathrm{EL}=$ Squamous Epithelial layer

Magnification for all slides: X10

Note: Arrows point to the edges of the vaginal squamous epithelial layer showing its thickness (height) at different stages of the menstrual cycle.

Figures'legend

The vaginal epithelial height (thickness) varies with stage of menstrual cycle. The squamous epithelium layer gradually thickens through out the proliferative/follicular/ovulatory phase (stage 1-4, Figures 2 (a-d),

(i) Postmenstrual phase (stage 1) (Figure 2a)

Our results showed that there was increase in both small and large intermediate cells as well as superficial cells leading to increase in epithelial height in comparison to menstrual phase. There
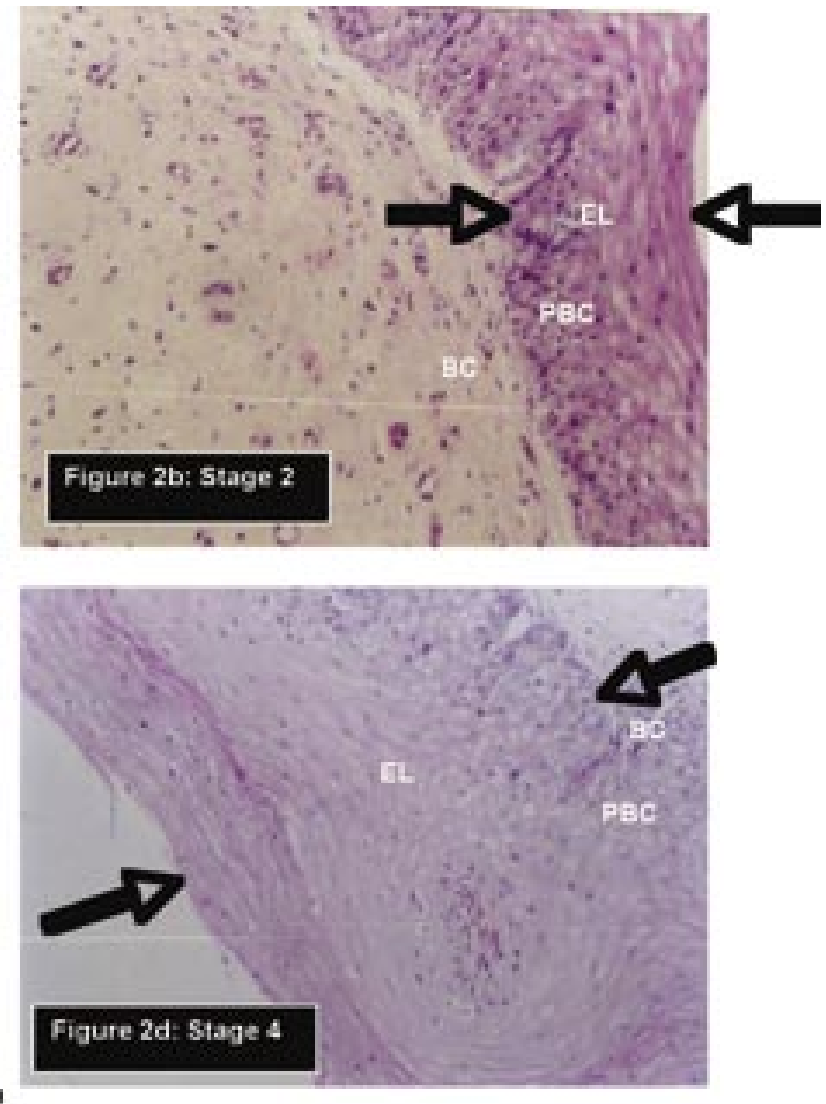

were also some parabasal and leucocytes, which were uniformly spread than, in menstrual phase.

(ii) Pre-ovulation (stage 2) (Figure 2b)

Our results showed that there was high number of superficial cells and a sharp rise in quantity of leukocytes and mucus than other stages (stage 1 and 7) leading to further increase in squamous epithelial height. Both superficial and intermediate cells were large in size. Anuclear and binuclear cells appeared. The epithelial layer was observed to be thicker than in the previous two stages (stage 1 and 7).

(iii) Ovulation phase ( stage 3) (Figure 2c)

Our results showed that there was abundance of evenly distributed superficial epithelial cells and consequently the height of vaginal squamous epithelium was thickest. Superficial cells increased in number and reached maximum at the end of the phase. There was also anuclear and binuclear superficial cells. 


\section{Figures 2(e-h)}

Haematoxylin and eosin staining of female baboon vaginal biopsy during the menstrual cycle (luteal, menstrual and pregnancy phases)

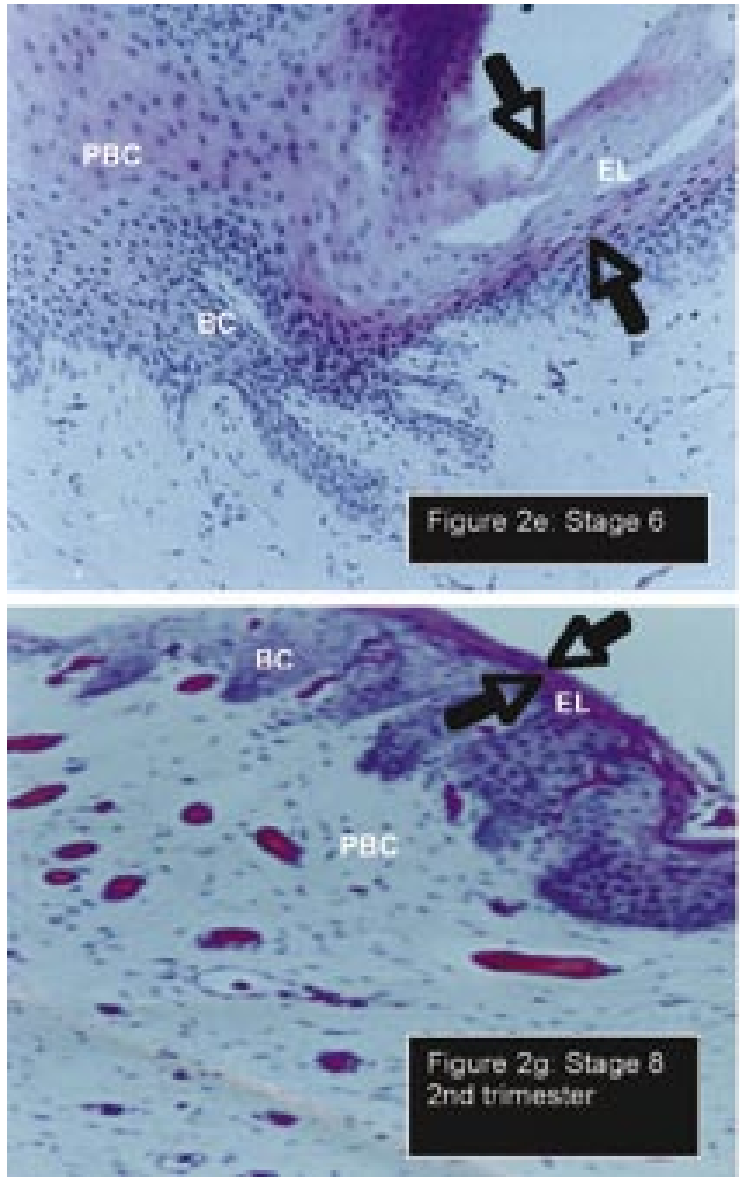

$\mathrm{BC}=$ Basal Cells

$\mathrm{PBC}=$ Parabasal Cells

$\mathrm{EL}=$ Squamous Epithelial layer

Magnification for all slides: X10

Note: Arrows point to the edges of the vaginal squamous epithelial layer showing its thickness at different stages of the menstrual cycle and pregnancy period

Figures'legend

The vaginal squamous epithelium layer becomes thin during the luteal phase (stage 6, Figure 2e) menstrual phase (stage 7, Figure 2f) and during pregnancy (stage 8 , Figures $2 g$ and $2 h$ ).

\section{(iv) Post-ovulation/secretory (stage 4) (Figure 2d)}

Our results showed that there was clumping of cells and flapping of cells leading to diminishing of epithelial layer height. The leukocytes began to appear. The cells appeared to be curling and folding. The placard and rosette arrangement

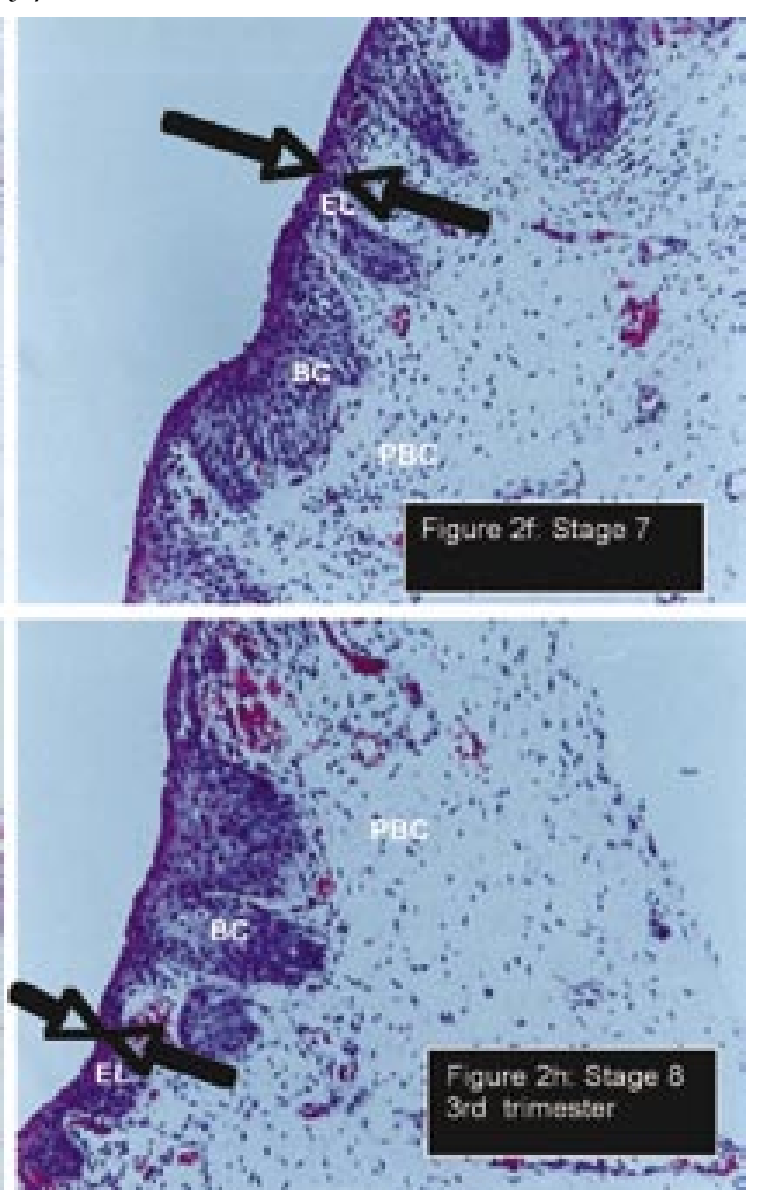

of cells remained high. The percentage of karyopyknotic cells was also high. The superficial cells were present but parabasal cells were lacking.

(v) Luteal phase/secretory (stage 6) (Figure 2e)

Our results showed that there was gradual diminution of the number of all superficial and upper intermediate and parabasal cells. The cells were observed to be smaller in size. Crowding of cells, wrinkling of cell membrane and loss of cell boundary was also evident. The mucus had lessened and cell had become more randomly arranged.

(vi) Premenstrual phase (stage 0) (Figure not shown) Our results showed that there was slight increase in superficial cells. Increment in total number of cells in comparison to luteal phase was noted. However, the cells were observed to be smaller in size. There was random arrangement of basal and parabasal cells and lessened mucus than in previous phase. 
(vii) Menstrual phase (stage 7) (Figure 2f)

The intermediate cells were observed to predominate. These intermediate and superficial cells however appeared diminished in size. The epithelial layer was very thin due to loss of cells. The glycogen contents and mucus levels were also at minimum. The number of leucocytes was very small.

(viii) Pregnancy phase (stage 8) (Figure $2 g$ and $2 h$ )

The epithelial layer height was small. The number of superficial and intermediate cells was small. Glycogen content is also very low.

\section{DISCUSSION}

Non-human primate models have been used for pre-clinical research to test the safety, mechanism of action and efficacy of new diagnostics or therapeutic approaches before they can be used in humans. A baboon model offers attractive features for such studies: Firstly, they are not endangered species, and are regarded as agricultural pests in many sub-Saharan African countries (8). Secondly, their reproductive physiology is well characterised and shown to be similar to those of humans (1). Thirdly, in the baboons it is possible to carry out repeated transcervical procedures and to haveeasier menstrual cycle follow-up by observations of the sex skin changes $(1,5,9)$. In the current study, we used the baboon to evaluate the relationship between baboon pereneal skin changes and vaginal epithelial thickness (height).

We have demonstrated for the first time that there are changes in squamous epithelium of vaginal tissue that correlates to the changes in the perineal sex skin of female olive baboon through out the menstrual cycle. Since sex skin changes are influenced by changes in the levels of steroid hormones such as oestrogen and progesterone $(9,10)$, its possible that these hormones regulate the vaginal epithelial thickness. Indeed, recent studies in rhesus monkey, showed that estradiol infusion increase the vaginal epithelial height and muscularity layer(11) and topical application of this hormone increase the thickness and cornification of the cervix vaginal epithelium (12). In normally cycling women, Patton et al (7) showed that the thickness of the ectocervical and vaginal epithelium changed significantly throughout the course of the menstrual cycle. In this study the vaginal epithelial was shown to increase throughout the course of the follicular phase, reaching peak at around the time of ovulation and then decreasing such that by the late luteal phase, the epithelium was at the thinnest. This finding is similar to our study where we have demonstrated that the vaginal epithelial layer is thickest during ovulation (stage 3) and thinnest during the late luteal phase (stage 6). We also demonstrated in this current study that there was an increased level of glycogen rich cells during the ovulation stage as compared to other stages (Table 1). The results are comparable to the ones in women, where, topical vaginal oestrogen treatment in women, improved the thin atrophic vaginal mucosa to a thick one making the epithelium cornified and increasing its glycogen content (13).

Although we did not carryout transvaginal simian immunodeficiency virus (SIV) inoculation at the various stages of the menstrual cycle, our data give an indirect support that a part from mucosal immunity, the heterosexual transmission efficiency of SIV in non-human primate may be influenced by the variation of the vaginal epithelium thickness which changes during the menstrual cycle, because the viral transmission efficiency is dependent on how easily the virus penetrates the epithelial layer $(10,14)$. The proliferative phase, which was observed to have highest epithelial height, would be expected to show least SIV transmission efficiency as compared to the luteal phase which had the least squamous epithelial height. Findings by other investigators have suggested that oestrogen and progesterone alter cervicovaginal epithelium which may change woman's susceptibility to HIV infection (15). Additionally this data supports the possibility that steroids hormones may complement SIV / HIV mucosal immunity in preventing transvaginal SIV / HIV transmission (15). Indeed, Smith et al., (12) using ovariectomised rhesus monkeys, demonstrated that topical vaginal estriol could protect against SIV vaginal transmission, while having no detectable systemic effect (12). However, it is unknown if such treatment could confer transvaginal SIV protection in normal non-ovariectomised monkeys. Since, most contraceptives contain progesterone and/or oestrogen, it has been argued that they can alter the vaginal epithelial thickness and hence influence the transvaginal transmission of HIV (15). A study in women on systemic long acting gestagen contraceptives (progesterone based contraceptives) revealed that they had an increased rate of HIV infection (16). These data indicate a possible correlation between use of hormonal contraception and HIV transmission efficiency.

A non-human primate model is critical for a detailed evaluation of the role of the vaginal epithelium and transvaginal sexually transmitted disease (STD) infections such as HIV. In a baboon model, unlike in women, it is practically possible to conduct detailed study on the role of hormones and transvaginal HIV/SIV transmission, a useful study which may lead to a better understanding of the mechanism that may change the susceptibility of women to HIV infection. In this study we have demonstrated that there are vaginalepithelial changes relative to the menstrual cycle, a phenomenon 
similar to women, a study which may be important for detailed evaluation of the recent suggestion that changes in vaginal epithelial thickness may change the women's susceptibility to HIV infection (15). Further studies on topical application of exogenous hormones/hormone based contraceptives may be required for detailed understanding of their effects on the vagina in the baboon and SIV transmission.

In conclussion, the studies indicate that in olive baboon, whose menstrual cycle has features similar to those of human, the vaginal epithelial height varies with stage of cycle with proliferative and luteal phases showing highest and lowest height respectively. These vaginal epithelial changes may play a role in enhancing transvaginal infections such as HIV.

\section{ACKNOWLEDGEMENTS}

To the technicians and veterinarians in the Animal Resource Department, Institute of Primate Research (IPR) for the daily follow-up of the baboon perineal skin staging, daily health monitoring and caring for the animals used in this study. We also thank Mr. Eric Omolo and Mrs. Mary Galo of Reproductive Biology Division, IPR, for technical assistance. Financial support was provided by the Institute of Primate Research (IPR) and Third World Academy of Sciences (TWAS).

\section{REFERENCES}

1. Stevens V.C. Some reproductive studies in the baboon. Hum. Reprod. Update. 1997; 3:533-540.

2. D'Hooghe T.M. Clinical relevance of the baboon as a model for the study of endometriosis. Fertil. Steril. 1997; 68: 613-625.

3. D'Hooghe, T. M., Kyama C.M., Chai, D. et al. Nonhuman primate models for translational research in endometriosis. Reprod. Sci. 2009; 16: 152 - 161.

4. Fazleabas A.T. A baboon model for inducing endometriosis. Methods Mol. Med. 2006; 121: 95-99.

5. Bambra C. and Eley R.M. Veterinary management and research techniques for reproductive studies in the baboon: A practical approach. $1^{\text {st }}$ Edition Basic Reproductive Biology of Baboon 1993; 29-40.

6. Ghanem K.G., Shah N., Klein R.S., et al. Influence of sex hormones, HIV status and concomitant sexually transmitted infection on cervicovaginal inflammation. J. Infect. Dis. 2005; 191: 358-366.

7. Patton D.L., Thwin S.S., Meier A., et al. Epithelial cell layer thickness and immune cell populations in the normal human vagina at different stages of menstrual cycle. Am. J. Obstet. Gynecol. 2000; 183:967-973.

8. Mwenda J.M. Sustainable utilization of Kenyan non human primate for biomedical conservation research. International perspectives, the future of nonhuman primate resources, proceedings of the workshop, National Academic Press Washington D.C 2003; 13-15.

9. Kling R.O and Westfahl K.P. Steroid changes during the menstrual cycle of the baboon (Papiocynocephalus) and human. Biol. Reprod. 1978;18:392-400.

10. Ochiel D.O., Wango E.O., Kigondu C.S. and Otsyula M.G. Effects of menstrual cycle on mucosal immunity to SHIV within the reproductive tract of baboons (papio anubis): preliminary findings. J. Med. Primatol. 2003; 32:161-169.

11. Kim N.N., Min K., Pessina M.A., et al. Effects of ovariectomy and steroid hormones on vaginal smooth muscle contractility. Int. J. Impot. Res. 2004; 16:43-50.

12. Smith S.M., Mcfford M., Sodora D., et al. Topical oestrogen protects against SIV vaginal transmission without evidence of systemic effect. AIDS. 2004; 18:1637-1643.

13. Felding C., Mikkelsen A.L., Clausen H.V., et al Preoperative treatment with estradiol in women scheduled for vaginal operation for genital prolapse. A randomized, double-blind trial. Mauritas. 1992; 15: 241-249.

14. Hu J., Gardner M.B. and Miller C.J. Simian immunodeficiency virus rapidly penetrates the cervicovaginal mucosa after intravaginal inoculation and infects intraepithelial dendritic cells. J. Virol. 2000; 74: 6087-6095.

15. Mingjia L., Short R. How oestrogen or progesterone might change a woman's susceptibility to HIV-1 infection. NZJ. Obstet. Gynaecol. 2002; 45: 472-475.

16. Martin H.L. Jr, Nyange P.M., Richardson B.A., et al. Hormonal contraception, sexually transmitted disease, and risk of heterosexual transmission of human immunodeficiency virus type 1. J. Infect. Dis. 1998; 178:1053-1059. 